WellBeing International

WBI Studies Repository

1986

\title{
Ethics, Welfare, and Laboratory Animal Management
}

David J. Allan

Queensland Institute of Technology

Judith K. Blackshaw

University of Queensland

Follow this and additional works at: https://www.wellbeingintlstudiesrepository.org/acwp_arte

Part of the Animal Experimentation and Research Commons, Animal Studies Commons, and the Laboratory and Basic Science Research Commons

\section{Recommended Citation}

Allan, D.J., \& Blackshaw, J.K. (1986). Ethics, welfare, and laboratory animal management. In M.W. Fox \& L.D. Mickley (Eds.), Advances in animal welfare science 1986/87 (pp. 1-8). Washington, DC: The Humane Society of the United States.

This material is brought to you for free and open access by WellBeing International. It has been accepted for inclusion by an authorized administrator of the WBI Studies Repository. For more information, please contact wbisr-info@wellbeingintl.org.

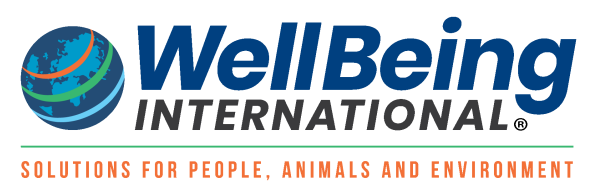




\title{
ETHICS, WELFARE, AND \\ LABORATORY ANIMAL MANAGEMENT
}

\author{
David J. Allan ${ }^{1}$ and Judith K. Blackshaw ${ }^{2}$
}

\section{Introduction}

Animals have been used in medical research from as far back as 129-199 A.D. when Galen, a Greek medical scientist, used a pig for his experiments. In the sixteenth and seventeenth centuries, anatomical dissections were carried out on animals; Galvani used frogs in 1791 for his experiments and the Russian physiologist, Pavlov, carried out his famous dog experiments in the early 1900s. Since this time, large numbers of animals have been used in biomedical and other research. In 1963 the first edition of "The Guide for the Care and Use of Laboratory Animals" was published, and the United States Public Health Service began to require all recipients of grants in which animals were used to adhere to these guidelines. There is now worldwide interest in welfare issues, and the ethics of using animals for research has been raised in many countries.

The study of ethics is the treating of moral questions and is concerned with right and wrong. There will always be differing opinions on the ethics of animal use which may raise dilemmas for workers. In a practical sense this has often been dealt with by drafting codes for the care and use of experimental animals. Adherence to a code, however, does not exclude the experimenter from actively considering ethical and welfare issues.

Three important issues in laboratory animal management are the ethics of using the animals for experimentation, the welfare of the animals being used, and the scientific validity of the selected species and number to be used.

\section{Ethical Considerations}

Animal Rights. - A distinction should be drawn between the concepts of animal welfare and animal rights. Advocates of animal welfare acknowledge that we have a right to use animals according to our needs and emphasize the maintenance of high standards of animal management. Animal rights organizations promote the complete cessation of all aspects of human "exploitation" of animals (Singer 1976).

The philosophy of animal rights has developed through the thoughts of a number of modern philosophers who have become involved in public debate on the ethics of animal experimentation. These debates and discussions have 
been used for criticizing many current practices involving animal use. Singer (1985) commented that although there were one or two nineteenth century thinkers who asserted that animals have rights, the serious political movement for animal liberation is a product of the 1970s. Several philosophers have written books on animal rights (e.g., Singer 1976; Regan 1983) which have become the basis for the animal liberation movement. Singer $(1980,1985)$ stated that from an ethical point of view, humans and nonhumans stand on an equal footing. That we use chimpanzees for experiments and yet would not do so with retarded humans of lower mental level is, in Singer's view (1976, 1980, 1985), an example of speciesism and is as indefensible as the most blatant racism. However, Singer $(1980,1985)$ is very careful to point out that he does not mean that animals have all the same rights as humans; he advocates equality of consideration of interests, not equality of rights. Where animals and humans have similar interests, those interests are to be counted equally, with no automatic discount just because one of the beings is not human. When Singer (1980) commented on animal experimentation he posed the question: What experiments on animals can be justified without speciesism? He answered: Only those experiments which would also be justified if performed on an orphaned, irreparably retarded human being at a comparable level of sentience and awareness. Exactly which experiments this criterion justifies depends on the extent to which one believes that it is permissible to sacrifice the interests of one human being to benefit another. Because Singer takes a broadly utilitarian view on these issues he can justify some experiments, but there are many that he cannot justify.

Regan (1983, 1985) regards himself as an advocate of animal rights and does not take Singer's utilitarian view. He believes there are fundamental differences between utilitarianism and the rights view. This is very apparent in the use of animals in science. For the utilitarian, whether the harm done to animals in pursuit of scientific ends is justified, depends on the balance of aggregated consequences for all those affected by the outcome (Regan 1983). The rights view is that an individual should never be harmed merely on the grounds that this will or might produce "the best" aggregate consequences. To do so is to violate the rights of the individual, and this is why the harm done to animals in pursuit of scientific purposes is wrong. So Regan (1985) is committed to total abolition of the use of animals in science, agriculture, sport, hunting, and trapping.

It is important to understand these views on the use of animals as they are an attempt to give a philosophical and ethical basis to the practice of using experimental animals. The most valuable outcomes of these discussions have been to heighten the awareness of the public and the animal researcher to the ethical issues involved when animals are used for research.

Animal Experimentation. - These divergent views raise the crucial issue of whether it is proper to use animals in scientific investigations and, if so, what ethical obligations we have to provide for their welfare.

Laboratory animals are presently used in a wide variety of experimental situations: 
i. scientific research-which studies the basic life processes, the cause of diseases, and the investigation of new therapies and drugs, with an aim to prevent, cure, or alleviate human and animal suffering,

ii. educational processes,

iii. experimental work on animal breeding and nutrition,

iv. diagnostic testing for disease in man or animals,

$\mathrm{v}$. development, production, and testing of commercial products, such as vaccines, antisera, shampoos, food additives, and cosmetics.

The British Veterinary Association has recently given a great deal of thought to the need for animal experiments (Seamer 1982) and supports the principle of the three R's.

i. Replace animals where possible, with valid alternatives.

ii. Reduce the number of animals needed for an experiment by the use of a planned design, so a statistically valid result can be obtained with the minimum number of animals.

iii. Refine the experiment and choose the most appropriate animal model.

Criticism of the use of animals for inessential experiments and the large numbers of animals used in experiments has led to questioning the obligations of the research worker to the animals. This has also stimulated the active consideration of alternatives and adjuncts which may be suitable to use in place of, or in conjunction with, some animal experiments.

Alternatives to Animal Experiments. - It is important to consider the alternatives which may be suitable to use in place of, or in conjunction with, animal experiments (Balls 1983).

i. A wide range of procedures could contribute to a reduction in the current reliance on animal experiments in toxicity testing (i.e., the LD50 test). These could include improved data storage, and more opportunity for the international exchange and use of this information. In the authors' opinion, needless repetition of toxicity tests occur and an international register of the toxicity of chemicals would help cut down the number of tests.

ii. Mathematical modelling using computer-assisted models of various biological processes are important adjuncts to the use of live animals. It must be recognized that development of these models is dependent on the amount and quality of the information used in their construction. This information may be derived from new animal experiments, and animals might also be needed to test the validity of the constructed model. Mathematical modelling is in the early stages of development but can be expected to increase in the near future.

iii. Use of vertebrate embryos or lower organisms has the advantage of acquiring rapid results on the general effects of chemicals on complete living organisms. Other alternatives include bacteria, algae, fungi, protozoans, coelenterates, plants, insects, echinoderms, and molluscs. Bacterial tests for mutagenicity are well established and are being used to make early decisions about new product development (quoted in Balls 1983).

iv. Man is the ultimate experimental animal in the final stages of testing any chemical intended for the use of man. Already human volunteers are widely 
used in the testing of cosmetics and toiletries. Occupational association has allowed the identification of many known human carcinogens. Cancers associated with occupations such as radiology and asbestos mining are examples of how man serves as the primary experimental subject.

v. In vitro techniques have been developed including the use of subcellular fractions, cell suspensions, tissue biopsies, tissue slices, whole organ perfusion, and tissue culture. Thus the classic Friedman-Lopham rabbit test for human pregnancy has been replaced by an in vitro technique (Stark 1983). The main potential advantage of in vitro methods is that information can be obtained in isolation, but this may be the main disadvantage as the animal body never works in isolation.

The trend towards alternatives will continue but they must be subjected to rigorous and critical independent assessment. Animal experiments and alternative methods will be used together for the foreseeable future.

Obligations of the Research Worker. - It is the humane use and care of all animal life that defines an ethical and conscientious society. When animals are used for research, there is a clear obligation on those using the animals, and on those deriving benefit from such use to:

i. provide humane care and treatment,

ii. minimize pain and discomfort,

iii. avoid unnecessary use of animals.

There is an obligation on those using animals to be accountable for their proper use. This can be achieved by institutional, funding agency, and editorial responsibilities, and periodic reviews by ethics committees.

The institution should have strict codes for the care and use of laboratory animals, and the funding agencies should require adherence to these ethical codes. Nevertheless, the ultimate responsibility for preventing animal pain and suffering lies with the individual scientist.

In the final stage, before they consider publishing the work, editors of journals should make sure that the welfare of the experimental animals has been taken into account.

It should be considered a privilege to use experimental animals, and so their welfare must be assured.

\section{Welfare Considerations: The Animal and the Environment}

The environment is central to laboratory animal management and the welfare of the animal must be considered throughout the breeding-holding phase and the experimental phase.

The Breeding-Holding Phase. - The laboratory animals used for experimental purposes have been selected and bred for many generations under laboratory conditions, and need a well-controlled environment to keep them healthy. The design of animal accommodations must take into account the variety of species held and the differing ages of the animals.

The environment influencing the animal during this phase has physical, nutritional, and general biological components.

i. physical environment 
Factors which affect the health and welfare of the animals include noise, temperature, humidity, ventilation, and light/dark cycles.

It is known that noise can adversely affect animals which rely on hearing for courtship and mating behavior (Fletcher 1976). Under normal animal house conditions the ambient noise levels are $42-44$ decibels and may rise to 54-68 decibels during feeding and cage cleaning. In most cases the duration of this higher level noise is not long enough to cause problems (Fletcher 1976). Sudden noises are often more of a problem than intensity. Auditory fire alarms with gradual buildup cause few of the problems seen with sudden onset alarms. Similarly, crashing feed can lids or other intrusive noises caused by workers in the room are likely to be stressful, affecting productivity and physiological stability.

The optimum temperature range for most laboratory animals is $19-23^{\circ}$ Centigrade (Harkness and Wagner 1983), and ideally the temperature should not vary more than $2^{\circ}$ Centigrade from an average level.

Control of humidity is necessary for the health and comfort of the animals and staff. A range of 30-70\% saturation is acceptable for most animal houses (Harkness and Wagner 1983).

Recirculation of air in an animal house is not advisable as dust and microorganisms could be widely distributed. Room air changes with fresh or filtered air should be between ten and fifteen complete air changes per hour to achieve uniform ventilation, depending on the arrangement and size of the cages and the stocking density (Harkness and Wagner 1983; Lane-Petter 1976).

Direct sunlight is usually excluded from the animal house because it makes the control of lighting and temperature difficult. A lighting cycle of 12 hours daylight and 12 hours darkness ensures a constant breeding cycle throughout the year for most species.

ii. nutritional environment

While the nutritional requirements of some laboratory animals are fairly well documented (Coates 1976), knowledge about the nutritional requirements of most nonhuman primates and many other species is largely or totally lacking and in need of research attention. Laboratory animals should have access to a clean, reliable water supply and wholesome, clean, nutritious palatable food on a regular basis to ensure the appropriate intake of protein, fat, carbohydrate, vitamins, salts, minerals, and fiber.

iii. biological environment

Major aspects of the biological environment are the control of communicable disease, and the management of the social environment.

The control of disease organisms (parasites and pathogenic microorganisms) is a fundamental requirement for successful laboratory animal management and influences the welfare of each animal. Hygiene in the animal house is directed mainly at the prevention of infections and infestations in the whole animal population. This is achieved by the quarantine of incoming animals, restricted entry of people, the maintenance of physical barriers (e.g., flyscreens, air locks, and air curtains), adequate sterilization procedures, 
and the incorporation of design features that enable the easy and effective cleaning of fixed and moveable structures. Treatment of infection is an aspect of laboratory animal medicine involving specialized diagnostic and management procedures.

People, too, represent a very important aspect of the social environment of animals. The technician or caretaker should be recognized by colony individuals as a dominant member of the social hierarchy. Colonies that fail to recognize this role of the technician/caretaker are likely to inadvertently increase the stress of the colony as demonstrated by a multitude of conditions including increased susceptibility to disease, reduced fertility, and aggression.

The provision of an optimum social environment will ensure the maximum output from each unit of the breeding colony and will help maintain the good health and welfare of the growing animals. The housing and breeding systems selected for each species are the main factors determining the social environment for reproduction. For example, the permanently mated monogamous breeding system is suitable for rats and mice, but unsuitable for rabbits which are temporarily mated (Festing 1976). Design of the reproductive environment also needs an understanding of the behavioral characteristics of the different species. Rats may not litter on a nesting place even when supplied with nesting material, and the young may fall through a grid floor. The cage should have a solid floor and soft nesting materials to prevent possible injury or loss of the young. The social environment of growing animals is influenced by density, mixing of littermates, and sex. The failure to recognize this may jeopardize their health and even survival.

The Experimental Pbase. -.-The welfare of animals used in the experimental environment is ultimately the responsibility of the research worker. Consideration must be given to handling and restraint, experimental procedures (e.g., anesthesia, blood collection), and euthanasia.

The techniques of handling and restraint of each species should be mastered so that the animals are not injured, unduly stressed, or able to inflict injury on the handler. Most experimental animals become accustomed to handling but special restraint methods are necessary for some species, e.g., support of the rear quarters of a rabbit will prevent kicking of the hind legs and so prevent fracture of its lumbar vertebrae or scratching of the handler.

Experimental procedures need to be planned in detail and implemented by personnel experienced in the techniques. Minimization of pain can be achieved by thoughtful selection of the experimental technique and the use of anesthesia, analgesic, or sedative agents where necessary. Drugs that should be favored for use in laboratory animals meet the following criteria: Simple equipment and easy manipulative technique for administration; a reliable action and a wide safety margin in the species being used; nonvolatile, nonexplosive, and nontoxic to the worker during storage and use; cost-effective. Injectable general anesthetic agents, for example, should be considered in preference to an explosive volatile agent such as ether for routine use in the laboratory. 
Euthanasia of laboratory animals is carried out in three main circumstances: Culling of unwanted animals, relief of suffering in an individual animal, or as the end-point of an experiment. When undertaking euthanasia, the welfare of the animal and the personnel must be considered. To safeguard the welfare of the animal, the technique chosen should achieve quick, quiet, and painless death and should not induce fear, apprehension, or panic in the animal. Other animals should be protected from the sight, sound, or smell of the procedure. The welfare of the personnel is protected by adopting a procedure that is physically and chemically safe and aesthetically acceptable. Euthanasia should not be carried out in a public or communal area.

\section{Conclusion}

The ethics and welfare considerations in laboratory animal management are multiple and complex, involving animals in all phases of their life cycle. In an intensive laboratory animal colony, the welfare of individual animals within the group is of prime importance and is not adequately reflected by measures of overall productivity. Management decisions can be difficult in situations where individual and group welfare interests conflict, e.g., the culling of aged animals from a breeding colony. When planning animal management or experimental procedures, the well being of the animal house staff and research workers should not be overlooked.

\section{Endnotes}

${ }^{1}$ Senior Lecturer, Pathology, Dept. of Medical Laboratory Science, Queensland Institute of Technology, Brisbane, Australia, 4000.

2 Lecturer in Animal Behaviour, Dept. of Animal Sciences and Production, University of Queensland, St. Lucia, Australia, 4067.

\section{References}

Balls, M. 1983. Alternatives to experimental animals. Vet. Rec. 113 (7): 398-401.

Coates, ME. 1976. The nutrition of laboratory animals. In: The UFAW Handbook on the Care and Management of Laboratory Animals. Edinburgh, London and NY: Churchill Livingston. PP. 27-56.

Festing, MF. 1976. Production methods. In: The UFAW Handbook on the Care and Management of Laboratory Animals. Edinburgh, London and NY: Churchill Livingston. pp. 57-73.

Fletcher, JL. 1976. Influence of noise on animals. In: Control of the Animal House Environment. Laboratory Aninal Handbooks 7. London: Laboratory Animals Ltd. pp. 51-62.

Harkness, JE and Wagner, JE. 1983. The Biology and Medicine of Rabbits and Rodents. Philadelphia: Lea and Febiger.

Lane-Petter, W. 1976. The animal house and its equipment. In: Tbe UFAW Handbook on the Care and Management of Laboratory Animals. Edinburgh, London and NY: Churchill Livingston. pp. 74-94.

Regan, T. 1983. Tbe Case for Animal Rights. London, Melbourne and Henley: Routledge and Kegan Paul.

-. 1985. The case for animal rights. In: In Defence of Animals. Singer, P. ed. Oxford: Basil Blackwell Pub. Ltd.

Seamer, JH. 1982. B.V.A. Policy on animal experimentation. Vet. Rec. 110(1I): 241-44. 
Singer, P. 1976. Animal Liberation: Towards an End to Man's Inbumanity to Animals. London: Jonathan Cape Ltd.

- 1980. Animals and humans as equals. Anim. Reg. Stud. 2: 165-74.

-. 1985. Prologue. Ethics and the new animal liberation movement. In: In Defence of Animals. Singer, P. ed. Oxford: Basil Blackwell Pub. Ltd.

Stark, DM. 1983. Developing replacements to whole animal experimental systems. Calif. Vet. 37(1): 89-90. 